\title{
Resistance to the tetracyclines and macrolide- lincosamide-streptogramin group of antibiotics and its genetic linkage - a review
}

\author{
Durdica Marosevic ${ }^{1 *}$, Marija Kaevska', Zoran Jaglic ${ }^{1}$ \\ ${ }^{1}$ Veterinary Research Institute, Brno, Czech Republic \\ Marosevic D, Kaevska M, Jaglic Z. Resistance to the tetracyclines and macrolide-lincosamide-streptogramin group of antibiotics and its \\ genetic linkage - a review. Ann Agric Environ Med. 2017; 24(2): 338-344. https://doi.org/10.26444/aaem/74718

\begin{abstract}
I Abstract that have large consumption rates in both veterinary and human medicine, such as the tetracyclines and macrolidelincosamide-streptogramin (MLS) group of antibiotics. A high load of these agents increases the risk of transmission of resistant bacteria and/or resistance determinants to humans, leading to a subsequent therapeutic failure. An increasing incidence of bacteria resistant to both tetracyclines and MLS antibiotics has been recently observed. This review summarizes the current knowledge on different tetracycline and MLS resistance genes that can be linked together on transposable elements.
\end{abstract} \\ An excessive use of antimicrobial agents poses a risk for the selection of resistant bacteria. Of particular interest are antibiotics
}

- Key words

antibiotics, genetic determinants of resistance, transposons, transmission of resistance

\section{INTRODUCTION AND BACKGROUND}

An excessive use of antimicrobial agents poses a risk for the selection of resistant bacteria, which could be either causative agents of a specific disease or a reservoir of genetic determinants of resistance. The latest surveillance report on antimicrobial consumption in the community (i.e. outside hospitals) lists macrolides and tetracyclines as the third and fourth most commonly used subgroups of antibacterials in Europe [1]. Even more pronounced, however, is their use in veterinary medicine, where tetracyclines are the most frequently sold therapeutic antibiotics (37 \%), and macrolides account for $8 \%$ of the total sales, and are the fourth most frequently sold antibiotic class for veterinary use within Europe [2]. Because of their wide usage in veterinary medicine, their presence in the environment and agriculture is ubiquitous. Table 1 lists the tetracycline and macrolidelincosamine-streptomycin (MLS) antibiotics that have been approved for human or veterinary use.

Tetracyclines are broad spectrum antibiotics discovered in the late 1940s. They block the attachment of charged aminoacyl-tRNA to the ribosomal acceptor (A) site, and so interfere with the protein synthesis by preventing the introduction of new amino acids to the nascent peptide chain. They are effective against a wide range of gram-positive and gram negative bacteria, chlamydiae, mycoplasmata, rickettsiae and protozoan parasites $[3,4]$. Due to their low cost, they have been widely used in veterinary medicine for the treatment of various infections, such as colibacillosis, chronic respiratory disease, enteritis and many others [3]. In Europe, tetracyclines belong to the most widely used veterinary antibiotics, ranging from 12.4 up to $102.8 \mathrm{mg} / \mathrm{kg}$ of produced meat [5]. Moreover, tetracyclines have also been used in aquaculture [6] and agriculture [7].

Address for correspondence: Marija Kaevska, Veterinary Research Institute, Brno, Czech Republic

E-mail:kaevska@vri.cz

Received: 6 January 2017; accepted: 14 April 2017; first published on June 2017

* Current address for author D. Marosevic: Bavarian Health and Food Safety Authority, Veterinärstraße 2, 85764 Oberschleißheim
Table 1. List of approved tetracyclines, macrolides, lincosamides and streptogramins for human or veterinary use in European Union (2011_ Adriaenssens, 1999_EMEA).

http://www.chemeurope.com/en/encyclopedia/ATC_code_J01. html\#J01AA_Tetracyclines

\begin{tabular}{|c|c|c|c|}
\hline Tetracyclines & Macrolides & Lincosamides & Streptogramins \\
\hline Chlorotetracycline $^{\mathrm{b}}$ & Azithromycin ${ }^{c}$ & Clindamycin ${ }^{c}$ & Pristinamycin ${ }^{c}$ \\
\hline Clomocycline $^{c}$ & Clarithromycin ${ }^{c}$ & Lincomycin ${ }^{\mathrm{b}}$ & $\begin{array}{l}\text { Quinupristin/ } \\
\text { Dalfopristinc }\end{array}$ \\
\hline Demeclocycline $^{c}$ & Dirithromycin ${ }^{c}$ & Pirlimycin $^{a}$ & Virginiamycin $^{a}$ \\
\hline Doxocycline $^{b}$ & Erythromycin ${ }^{b}$ & & \\
\hline Lymecycline $^{c}$ & Flurithromycin ${ }^{c}$ & & \\
\hline Metacycline $^{c}$ & Gamithromycin $^{a}$ & & \\
\hline Minocycline $^{c}$ & Josamycin $^{b}$ & & \\
\hline Oxytetracycline $^{a}$ & Kitasamycin $^{a}$ & & \\
\hline Penimepicycline $^{c}$ & Midecamycin ${ }^{c}$ & & \\
\hline Rolitetracycline $^{c}$ & Miocamycin ${ }^{c}$ & & \\
\hline \multirow[t]{2}{*}{ Tetracycline $^{\mathrm{a}}$} & Oleandomycin ${ }^{b}$ & & \\
\hline & Rokitamycinc & & \\
\hline \multirow[t]{9}{*}{ Glycylcyclines $^{c *}$} & Roxithromycinc & & \\
\hline & Spiramycin $^{\mathrm{b}}$ & & \\
\hline & Telithromycinc & & \\
\hline & Tildipirosin $^{\mathrm{a}}$ & & \\
\hline & Tilmicosin $^{a}$ & & \\
\hline & Tulathromycin $^{\mathrm{a}}$ & & \\
\hline & Troleandomycin $^{c}$ & & \\
\hline & Tylosin $^{a}$ & & \\
\hline & Tylvalosin ${ }^{a}$ & & \\
\hline
\end{tabular}

* A new class of antibiotics derived from tetracycline, with tigecycline as the only glycylcycline antibiotic approved for antibiotic use by now

a veterinary use only

beterinary and human use

chuman use only 
To-date, 59 tetracycline resistance genes (tet genes) have been described. They can mediate resistance to tetracyclines by three different mechanisms: ribosomal protection, efflux and enzymatic inactivation of the active compound $[8,9]$.

MLS antibiotics are three chemically distinct, but functionally similar antibiotic classes. Macrolides with mycarose sugars on the fifth carbon in the lactone ring, lincosamides and streptogramin A inhibit the peptidyl transferase reaction [10], whereas macrolides of the erythromycin group prevent the early events of peptide elongation, and streptogramin B blocks the exit tunnel through which the nascent peptide chains exit the ribosome, resulting in the release of incomplete peptides [10, 11].The first described macrolide erythromycin has a moderately broad spectrum of activity, while newer semi-synthetic derivatives (e.g. clarithromycin and azithromycin) have a broader spectrum and are used in human medicine for the treatment of upper and lower respiratory tract infections, infections of the skin and soft tissue, sexually transmitted diseases, community-acquired pneumonia and atypical Mycobacterium infections. Together with lincosamides, macrolides are also used for the treatment of group B streptocoocal infections, or for the intrapartum prevention of Streptococcus agalactiae neonatal infections in penicillin hypersensitive patients [12, 13]. In combination with fluoroquinolones, erythromycin is commonly used in the therapy of severe infections caused by Campylobacter spp. [5]. In veterinary medicine, macrolides (e.g. tylosin) are recommended for the treatment of respiratory infections in cattle, swine and poultry. Further indications include treatment of proliferative enteropathy, enteritis and arthritis in swine, necrotic enteritis in poultry, and mastitis in cattle caused by Gram-positive bacteria.

A total of 92 genes that confer resistance to MLS antibiotics have been described to-date [14]. They can be roughly divided into three groups, depending on the mechanisms by which they confer resistance to one or all of these groups of antibiotics. Three main mechanisms of resistance to MLS antibiotics have been described: methylation of rRNA (target modification), active efflux and inactivation of the antibiotic. Target modification is achieved via the action of the protein product of one of more than 42 different erm (erythromycin rRNAmethylase) genes. They confer crossresistance between macrolides, lincosamides and streptogramin B (so-called $\mathrm{MLS}_{\mathrm{B}}$ resistance) and evoke most concerns. Active efflux and inactivating enzymes represent two additional mechanisms of resistance that are targeted only to particular antibiotics or antibiotic classes. For example, mef genes encode for macrolide efflux, $m s r$ genes for efflux of macrolides and streptogramin B, and the $l s a$ gene for efflux of lincosamides and streptogramin $\mathrm{A}$.

There is a vast body of information overseen by traditional microbiologist on the non-antimicrobial use of tetracyclines and macrolides in clinic and research, as recently reviewed by Aminov [15]. This type of therapy often includes lowdose, long-term exposure to antibiotics, which promotes dissemination of antibiotic resistances among commensal and pathogenic microbiota. Some progress has been made in developing compounds that retain their immunomodulatory activities, while abolishing antimicrobial activities [15], but continuous efforts are necessary in order to completely circumvent the selective pressure exhibited on the microbiota through this type of therapy.
The occurrence of bacteria resistant to both tetracyclines and MLS antibiotics has been observed [16, 17, 18]. This review will summarize the current knowledge on the topic of genetic linkage of different tetracycline and MLS resistance genes, and possible risks coupled with it for public health.

\section{TETRACYCLINE AND MLS RESISTANCE GENES AND TRANSPOSONS}

Identification of antibiotic resistance genes provides valuable information; however, knowledge about their association with mobile genetic elements is crucial for assessment of the risk for acquisition and dissemination of antimicrobial resistance. Transposable elements are by definition 'specific DNA segments that can repeatedly insert into one or more sites in one or more genomes; [19]. They can be distributed on both chromosomes and plasmids, and are able to interact by recombination between elements and/or by transposition into other elements, forming all kinds of novel chimeric structures $[20,21]$. Their complex nomenclature has been revised, and since 2008 all newly-discovered, fully sequenced and/or functional autonomously transposable elements that show $<100 \%$ sequence identity with the closest relative, were designated with a new Tn number. The acronyms ICE (integrative conjugative elements) and IME (integrative mobilizable element) are retained, but now interchangeable with CTn or MTn for conjugative transposon or mobilizable transposon, respectively, if conjugation or mobilization can be proved [22]. The first conjugative transposon identified in bacteria was Tn916 from E. faecalis[23], and was carrying the tetracycline resistance. Since then, a vast amount of different transposable elements have been identified, including those that carried several resistance and virulence genes [24]. Under the pressure of any of antibiotics to which the element confers resistance, the whole transposon is retained and, accordingly, multiple antibiotic resistance genes remain in the population. They can persist for decades in animal husbandry due to coselection, fitness and other phenomena [25]. An overview of transposons and selected mobile genetic elements conferring resistance to tetracyclines and/or MLS antibiotics discussed in this review is given in Table 2 and Figure 1.

There is a variety of transposons conferring tetracycline resistance. They are most often associated with tetracycline resistance, carry the tet $(\mathrm{M})$ gene and belong to the Tn916 transposon family. An excellent review on this topic was recently published and is recommended for more information on the subject [19]; however the main focus of this study are transposons carrying both resistance determinants, against tetracycline and MLS antibiotics, some of which belong to the Tn916 transposon family and will be discussed in detail. Elements associated with MLS resistance are the Tn917 transposon that carries the erm (B) gene [26] or MEGA element (macrolide efflux genetic assembly, 5.5kb) that carries the $m e f(\mathrm{E})-m s r(\mathrm{D})$ operon [27]. The Tn916 transposon family has a broad host range and transfer readily to a wide variety of Gram-positive and Gram-negative bacteria [19]. The integrase (int) and excisase ( $x$ is) genes used for identification of this group of transposons are indistinguishable by PCR methods from the int and xis genes of the Tn 1545 transposon [28]. They differ by only one nucleotide over approximately $2 \mathrm{~kb}$. Moreover, the tet $(\mathrm{M})$ genes from these two different transposons exhibit $94.5 \%$ nucleotide identity. Nevertheless, 


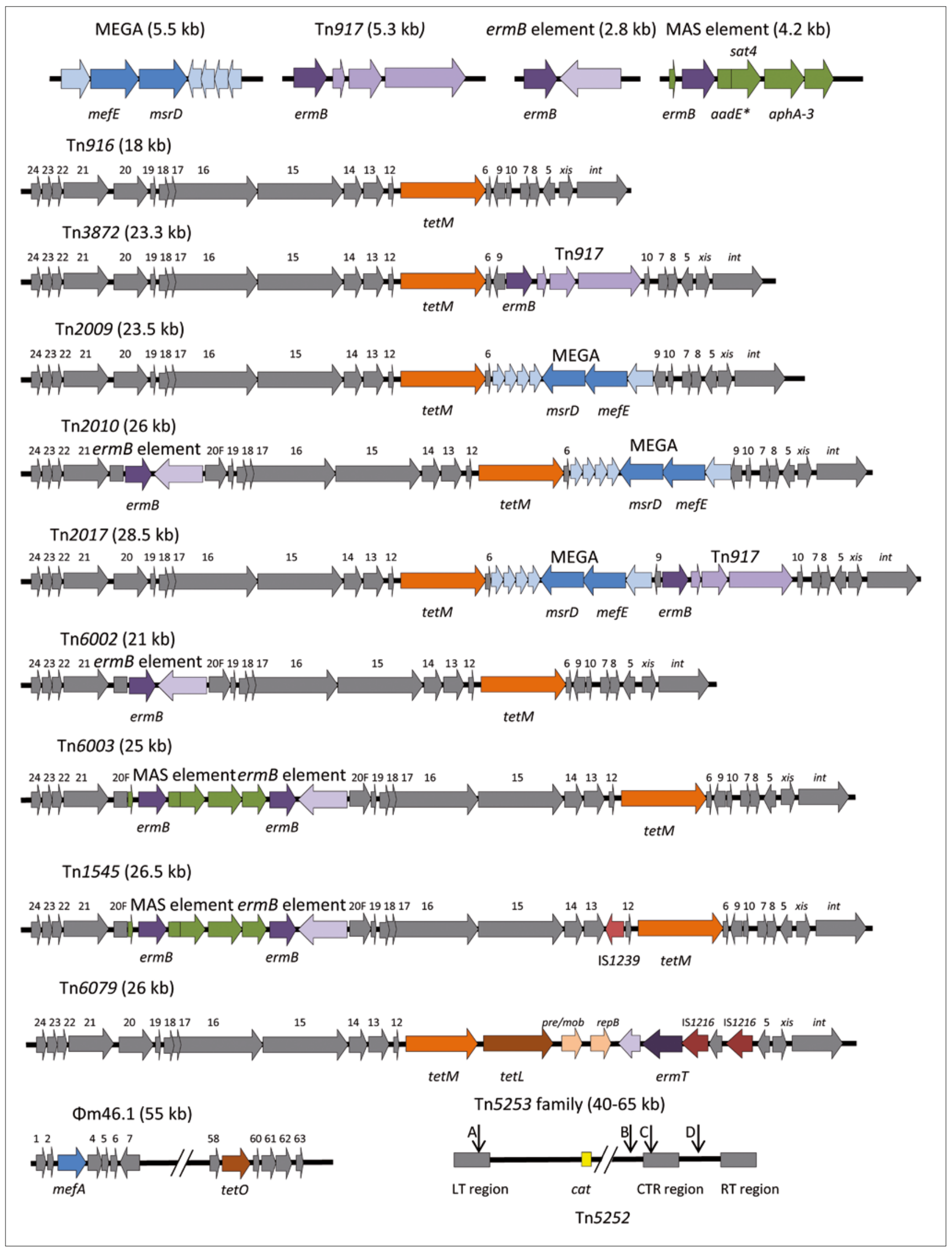

Figure 1. Schematic drawing of transposons and selected mobile genetic elements conferring resistance to tetracyclines and/or MLS antibiotics discussed in this review. Tn5253 transposon family is shown as a Tn5252 element (LT, left terminal region; CTR, conjugal-transfer related region; $\mathrm{RT}$, right terminal region) with indicated (arrows) insertion sites of Tn5251 or other Tn916-like transposons (A, Tn6002; B, Tn5251/Tn916 or SpnRi3ermB-like element; C, Tn916 or Tn6002; D, Tn916, Tn6002, Tn2009 or Tn3872) 
Table 2. Summary of transposons conferring resistance to tetracycline and/or MLS discussed in this review

\begin{tabular}{|c|c|c|c|c|}
\hline Transposon & tet gen & Comments & Size & Reference \\
\hline Tn916* & tet(M) & & $18 \mathrm{~kb}$ & $\begin{array}{l}\text { (Franke and } \\
\text { Clewell, 1981) }\end{array}$ \\
\hline Tn917 & & $\operatorname{erm}(B)$ & $7 \mathrm{~kb}$ & $\begin{array}{l}\text { (Shaw and } \\
\text { Clewell, 1985) }\end{array}$ \\
\hline MEGA & & mef(A)-msr(D) operon & $5.5 \mathrm{~kb}$ & $\begin{array}{l}\text { (Del Grosso } \\
\text { et al. 2006) }\end{array}$ \\
\hline $\operatorname{Tn} 1545^{*}$ & tet(M) & $\begin{array}{l}\text { MAS and erm(B) elements } \\
\text { inserted into Tn916-like } \\
\text { structure }\end{array}$ & $26.5 \mathrm{~kb}$ & $\begin{array}{l}\text { (Cochetti et al. } \\
\text { 2008) }\end{array}$ \\
\hline CTnDOT & $\begin{array}{l}\text { tet }(\mathrm{Q}) \text { or } \\
\text { tet }(\mathrm{X})\end{array}$ & $\operatorname{erm}(F)$, erm $(B)$ and aad & $65-100 \mathrm{~kb}$ & $\begin{array}{l}\text { (Gupta } \\
\text { et al. 2003; } \\
\text { Shoemaker } \\
\text { et al. 2001) }\end{array}$ \\
\hline $\operatorname{Tn} 2009^{*}$ & tet(M) & $\begin{array}{l}\text { MEGA element inserted } \\
\text { into Tn916-like structure }\end{array}$ & $23.5 \mathrm{~kb}$ & $\begin{array}{l}\text { (Del Grosso } \\
\text { et al. 2004) }\end{array}$ \\
\hline $\operatorname{Tn} 2010^{*}$ & tet(M) & $\begin{array}{l}\text { erm(B) element inserted } \\
\text { into Tn2009 }\end{array}$ & $26 \mathrm{~kb}$ & $\begin{array}{l}\text { (Del Grosso } \\
\text { et al. 2006; } \\
\text { Li et al. 2011) }\end{array}$ \\
\hline $\operatorname{Tn} 2017^{*}$ & tet(M) & $\begin{array}{l}\text { Tn917 inserted into } \\
\text { Tn2009 }\end{array}$ & $28.5 \mathrm{~kb}$ & $\begin{array}{l}\text { (Del Grosso } \\
\text { et al. 2009) }\end{array}$ \\
\hline $\operatorname{Tn} 3872^{*}$ & tet(M) & Tn917 inserted into Tn916 & $24 \mathrm{~kb}$ & $\begin{array}{l}\text { (Cochetti } \\
\text { et al. 2007; } \\
\text { McDougal } \\
\text { et al. 1998) }\end{array}$ \\
\hline Tn5253 & tet(M) & $\begin{array}{l}\text { Tn916-like transposon } \\
\text { inserted into Tn5252 } \\
\text { carrying the cat gene }\end{array}$ & $40-65 \mathrm{~kb}$ & $\begin{array}{l}\text { (Ayoubi et al. } \\
\text { 1991; Mingoia } \\
\text { et al. 2011) }\end{array}$ \\
\hline $\operatorname{Tn} 6002^{*}$ & tet(M) & $\begin{array}{l}\text { erm(B) element inserted } \\
\text { in Tn916 }\end{array}$ & $21 \mathrm{~kb}$ & $\begin{array}{l}\text { (Warburton } \\
\text { et al. 2007) }\end{array}$ \\
\hline Tn6003* & tet(M) & $\begin{array}{l}\text { MAS element inserted into } \\
\text { Tn6002 }\end{array}$ & $25 \mathrm{~kb}$ & $\begin{array}{l}\text { (Cochetti et al. } \\
\text { 2007) }\end{array}$ \\
\hline Tn5385 & tet(M) & $\begin{array}{l}\text { tet(M) (Tn5381); aac(6')- } \\
\text { aph( }\left(2^{\prime \prime}\right)(\operatorname{Tn} 4001) ; \operatorname{erm}(B) \\
\text { and merRAB (Tn5384); bla } \\
\text { (Tn552); aadE }\end{array}$ & $65 \mathrm{~kb}$ & $\begin{array}{l}\text { (Rice and } \\
\text { Carias, 1998) }\end{array}$ \\
\hline Tn6079* & $\begin{array}{l}\text { tet }(\mathrm{M}) \\
\text { and tet(L) }\end{array}$ & $\begin{array}{l}\text { Tn916/Tn1545-like } \\
\text { transposon carrying the } \\
\text { erm }(T) \text { gene }\end{array}$ & $26 \mathrm{~kb}$ & $\begin{array}{l}\text { (de Vries et al. } \\
\text { 2011) }\end{array}$ \\
\hline ICESp2905 & tet(O) & $\begin{array}{l}\text { erm(A) (ICESp2907 } \\
\text { integrated into ICESp2906) }\end{array}$ & $65 \mathrm{~kb}$ & $\begin{array}{l}\text { (Brenciani } \\
\text { et al. 2011; } \\
\text { Giovanetti } \\
\text { et al. 2012) }\end{array}$ \\
\hline
\end{tabular}

*Tn916-like elements

Tn916 and Tn1545 differ in size (18 vs. $25.2 \mathrm{~kb})$ and genetic content. In addition to the tet $(\mathrm{M})$ gene, Tn 1545 also harbours other determinants of resistance, i.e. the MAS (macrolideaminoglycoside-streptothricin) element and the erm(B) element [29]. Thus the co-selection of tetracycline and $\mathrm{MLS}_{\mathrm{B}}$ resistance may occur via the Tn 1545 transposon, and might be underestimated if isolates were screened only with int/xis specific primers $[18,30]$. A new Tn6079 conjugative transposon of the Tn916/Tn1545-like family that harbours two tetracycline resistance genes $[$ tet $(\mathrm{M})$ and $\operatorname{tet}(\mathrm{L})]$, and one gene conferring $\mathrm{MLS}_{\mathrm{B}}$ resistance $[\operatorname{erm}(\mathrm{T})]$ was recently identified in samples from an infant faecal fosmid library [31]. The presence of genetic determinants of resistance to both tetracyclines and MLS antibiotics was also described for other large transposons, such as the CTnDOT family, Tn2009, $\operatorname{Tn} 2010, \operatorname{Tn} 2017, \operatorname{Tn} 3872, \operatorname{Tn} 5253, \operatorname{Tn} 6058, \operatorname{Tn} 5385$,
Tn6002 and Tn6003 that arose as a combination of smaller transposons [20, 27, 32, 33, 34].

CTnDOT family transposons are large conjugative transposons from Bacteriodes spp. that carry resistance genes against tetracycline $(\operatorname{tet}(\mathrm{X})$, tet $(\mathrm{Q}))$ and MLS antibiotics $(\operatorname{erm}(\mathrm{B}), \operatorname{erm}(\mathrm{F}), \operatorname{erm}(\mathrm{G}))$ [35]. Their excision and conjugative transfer is dependent on tetracycline, although CTnDOTpositiveBacteriodetes spp. are not always tetracycline resistant due to their anaerobic nature and the fact that tetracycline resistance mediated by the tet $(\mathrm{X})$ gene is oxygen dependent $[4,34]$, they can serve as resistance reservoir for other pathogenic bacteria. Dissemination of tet $(\mathrm{X})$ resistance gene is of special concern because it confers resistance also against third generation tetracycline tigecycline[36]. Although the use of this antibiotic is strictly regulated, tet $(\mathrm{X})$ has already been observed among pathogenic bacteria [37], and sequence similarity of flanking regions around tet $(\mathrm{X})$ suggest that its spread is most likely due to horizontal transfer of transposons from the CTnDOT family [38].

Tn3872 is a composite element resulting from the insertion of the erm(B)-containing Tn917 transposon into orf9 of Tn916. The association between mefEmsrD and tet(M) was found in Tn2009 transposons that have the MEGA element inserted into a Tn916-like structure [20]. In addition to that, $\operatorname{Tn} 2010$ and Tn 2017 carry the erm (B) gene due to the insertion of the erm(B) element or Tn917, respectively, into a Tn2009 like structure $[27,39]$. Tn6002 is an element resulting from the insertion of an erm (B)-containing DNA fragment (the erm (B) element) into Tn916[33, 40]. Tn6003 carries determinants of resistance to aminoglycosides and streptothricin due to the MAS element, which can circularise, excise and turn back Tn6003 into Tn6002[32, 41].

Tn5253-like transposons are large composite transposons that consist of a Tn916-like element (originally designated as Tn5251) conferring tetracycline/MLS resistance, which is inserted into the Tn5252 element that harbours the cat (chloramphenicol) resistance gene [42]. Members of this diverse transposon family are often referred to as ICE elements, followed by an acronym of the species where they were discovered, and a unique number (i.e. ICESp2905) [43]. Tn5385 is a composite $65 \mathrm{~kb}$ large transposon comprising several smaller mobile elements, including an $18-\mathrm{kb}$ conjugative transposon (Tn5381) conferring resistance to tetracycline $[$ tet $(\mathrm{M})]$, a 26-kb transposon (Tn5384) conferring $\mathrm{MLS}_{\mathrm{B}}$ resistance (originally named erm(AM)], but now renamed as $\operatorname{erm}(\mathrm{B})$, as well as resistance to gentamicin $\left(\operatorname{aac}\left(6^{\prime}\right)-\operatorname{aph}\left(2^{\prime \prime}\right)\right)$ and mercuric chloride (merRAB), and a Tn552-like staphylococcal beta-lactamase transposon conferring resistance to penicillins (bla). The transposon further confers resistance to streptomycin via the aadE gene [29]. ICESp2905 is a widespread erm(A)- and tet(O)carrying genetic element of $S$. pyogenes, resulting from one ICE (ICESp2907) being integrated into another ICE (ICESp2906) of clostridial origin [44]. Originally, the MLS resistance determinant was named erm(TR), but it has been renamed to $\mathrm{erm}(\mathrm{A})$.

Giovanetti et al. [45] genotyped clinical isolates of S.pyogenes, and in addition to the $\operatorname{erm}(\mathrm{B})$ and tet $(\mathrm{M})$ genes, they identified a new genetic linkage between the tet $(\mathrm{O})$ and $\operatorname{erm}(\mathrm{A})$ or mef(A) genes. The authors demonstrated that the tet $(\mathrm{O})$ gene moved in conjugation experiments with and without the erm(A) gene, but always with the mef(A) gene. 
This association of tet $(\mathrm{O})$ and $m e f(\mathrm{~A})$ is due to the prophage $\Phi m 46.1$ identified in $S$. pyogenes [46]. The association of tet $(\mathrm{O})$ with the $\operatorname{erm}(\mathrm{B})$ gene was further described by Martel et al. [47]. All in all, as more sequence information is revealed, and new functional metagenomics approaches are applied in the research of the resistome, it is reasonable to expect that new transposable elements will continue to be discovered. Nevertheless, their functionality has to be proved in order to be designated by a new Tn number $[22,31]$.

\section{TRANSMISSION OF TETRACYCLINE AND MLS RESISTANCE}

In vitro transfer of antimicrobial resistance has been studied by many authors. Vignaroli et al. [48] investigated isolates of enterococci co-resistant to tetracycline and erythromycin originating from meat and faeces of chickens and pigs. They found that under in vitro conditions the isolates from faeces more readily transferred the resistance to enterococci of human origin. Jasni et al. [49] demonstrated reciprocal genetic exchange between $E$. faecalis and C. difficile, where the Tn5397 transposon carrying the tet $(\mathrm{M})$ gene was incorporated at a single specific target site. Wasels et al. [50] demonstrated the transfer of Tn6194 that carries the erm(B) gene between $C$. difficile and E. faecalis. Florez et al. [51] identified a Tn916-like transposon carrying the tet $(\mathrm{M})$ gene in plasmids from two Lactococcus lactis strains isolated from raw milk starter-free cheese. Conjugation experiments have shown that only the transposon, but not the whole plasmid, could have been transferred from L. lactis to E. faecalis. Enterococci originating from a total production chain of swine meat commodities were shown to successfully transfer the Tn916/1545 transposon family carrying the tet $(\mathrm{M})$ gene to other enterococci and $L$. innocua in both filter mating experiments and mating trials performed in meat matrices [52]. Transfer of tetracycline and erythromycin resistances from a human E. faecalis isolate was also demonstrated in a sausage fermentation model, even without antibiotic pressure and as early as within two days of fermentation [53]. In this model, transconjugant bacterial strains were identified among enterococci, pediococci, lactobacilli and staphylococci. In another study, a higher transfer rate for both vancomycin and tetracycline resistance was observed in fermented sausages compared to cheese [54]. Transfer of tetracycline resistance (i.e. the tet $(\mathrm{M})$ gene) from Lactobacillus isolates originating from fermented dry sausages to E. faecalis and L. lactis was demonstrated in conjugation experiments by Gevers et al. [55]. Although the transposon Tn2009 was originally identified in S. pneumoniae as nonmobilizable[20], in a later study, however, its conjugation was proved between a plenty of various bacteria, such as Acinetobacter junii, Citrobacter spp., E. coli, Enterobacter cloacae, Klebsiella spp., Pantoeaagglomerans, Proteus spp., Pseudomonas spp., Ralstoniapickettii,Stenotrophomonasmalto philia, E. faecalis, Neisseria mucosa and Neisseria perflava[56]. Even the large Tn5253 transposon or its related variants were conjugally transferred under laboratory conditions from $S$. pneumoniae to $S$. pyogenes and other streptococci, as documented in previous reports $[42,57]$.

Transfer of antimicrobial resistance, however, is highly influenced by the complexity of microflora and its interactions with the host. Moreover, it is presumed that in vitro models underestimate the potential risk for resistance transfer compared to in vivo models $[58,59]$. Therefore, to appropriately assess the risk for horizontal spread of antimicrobial resistance, many authors have recently performed experimental studies under in vivo conditions. Moubareck et al. [60] carried out experiments on gnotobiotic mice, and demonstrated the transfer of vanA (vancomycin resistance) and erm(B) among enterococci colonising the intestine. Although tylosin did not significantly increase the transfer of vancomycin resistance under in vitro conditions, it significantly increased intestinal colonization of the treated mice by vancomycin-transconjugants. A similar observation was reported by Doucet-Populaire et al. [61], who found that administration of tetracycline to gnotobiotic mice increased by 20 -fold the transfer of Tn1545 from E.faecalis to L. monocytogenes. On a model of gnotobiotic mice, Jacobsen et al. [62] demonstrated that the tet $(M)$ and erm(B) genes may transfer from Lactobacillus plantarum originating from fermented sausages to human isolates of E. faecalis. This finding supports the hypothesis that microorganisms of food origin may represent an important source of genetic determinants of resistance for microflora colonising human intestines. However, it should be kept in mind that experiments in gnotobiotic animals are performed under artificial conditions, i.e. in the presence of relatively high numbers of potential recipients and in the absence of competitive microflora. A recent in vivo study performed on commercial chickens has shown that the spread of a plasmidcarried $\operatorname{erm}(\mathrm{B})$ gene occurs not only within the faecal microbiota under both specific (tylosin and lincomycin) and non-specific (chlortetracycline) antibiotic pressure, but also in the absence of any antimicrobial pressure [63]. Moreover, all isolates of enterococci and streptococci that acquired the $\operatorname{erm}(\mathrm{B})$ gene were also resistant to tetracycline, which indicates that tetracycline may co-select for MLS $\mathrm{B}_{\mathrm{B}}$ resistance.

De Leener et al. [64] compared enterococci of human and porcine origin for their resistance profile against erythromycin and tetracycline. The $\mathrm{erm}(\mathrm{B})$ gene was found in $85 \%$ of porcine isolates and in all human isolates. The tet $(\mathrm{M})$ gene was found in 98 and $89 \%$ of the erm(B) positive isolates from pigs and humans, respectively. Among the $\operatorname{erm}(\mathrm{B}) /$ tet $(\mathrm{M})$ positive isolates, 77 and $70 \%$ isolates of porcine and human origin, respectively, carried a transposon of the $\operatorname{Tn} 916 / \operatorname{Tn} 1545$ family. The authors therefore suggested either a mutual spread of resistant enterococci between humans and pigs, or the existence of a common reservoir of resistant enterococci. The hypothesis that animals can be a source of resistant enterococci for humans could be supported by the findings of Sorensen et al. [65]. In the latter study, the survival of animal derived enterococcal strains in the human intestine was investigated in 18 volunteers. Transient intestinal carriage of resistant E. faecium of animal origin was detected up to 14 days after ingestion, suggesting that enterococci of animal origin can survive the gastric passage and multiply in the human intestine. This transient colonisation increases the risk for transfer of resistance determinants within human intestinal microbiota. De Vries et al. [31] investigated the diversity of microorganisms conferring tetracycline resistance in faecal samples from a healthy mother-infant pair one month after childbirth, and evaluated potential horizontal transfer of tetracycline resistance genes. For that purpose, faecal fosmid libraries were functionally screened for tetracycline resistance genes. In the mother library, identical tetracycline resistance gene 
sequences (predominantly tet $(\mathrm{O})$, followed by tet $(\mathrm{W})$ and tet $(\mathrm{X})$ ) were present in different bacterial families and even phyla, which may indicate horizontal transfer within the maternal gastrointestinal tract. Although tet genes other than those observed in the mother dominated in the infant library, tet $(\mathrm{O})$ and tet $(\mathrm{W})$ could also be detected in the infant faecal samples. Moreover, tet $(\mathrm{M}), \operatorname{tet}(\mathrm{L})$ and $\operatorname{erm}(\mathrm{T})$ were identified within a novel composite transposon Tn6079 in the infant library, which indicates a potential for the joint spread of tetracycline and erythromycin resistance within the infant's gut.

\section{CONCLUSIONS}

The antibiotic classes discussed in this review have been used for over 50 years, and still today have large consumption rates in human, but even more in veterinary medicine. They are listed by the World Health Organization as highly or even critically important in the case of macrolides. Rates of bacteria resistant to these classes of antibiotics depend on the source of isolation and history of antibiotic usage. Coresistance between tetracyclines and MLS antibiotics is often due to the occurrence of genetic determinants for tetracycline and MLS resistance on very promiscuous transposons that can interact, recombine and form all sorts of novel chimeric elements. This type of genetic linkage on transposons is of a very great concern. It increases the risk for transfer of resistances to pathogenic species, and enables the co-selection of all genes and their retention in the population, leading to therapeutic failure and severe consequences.

\section{Acknowledgements}

The study was supported by the by the Ministry of Education, Youth and Sports - NPU I (Project LO1218), and by the Ministry of Agriculture of the Czech Republic (Projects QJ1210301 and RO0516).

\section{REFERENCES}

1. European Centre for Disease Prevention and Control. Surveillance of antimicrobial consumption in europe 2012. 2014.

2. European Medicines Agency ESOVaC. Sales of veterinary antimicrobial agents in $26 \mathrm{eu}$ /eea countries in 2012. 2014

3. Chopra I, Hawkey PM, Hinton M. Tetracyclines, molecular and clinical aspects. J Antimicrob Chemother. 1992; 29: 245-277.

4. Shoemaker NB, Vlamakis H, Hayes K, Salyers AA. Evidence for extensive resistance gene transfer among Bacteroides spp. and among Bacteroides and other genera in the human colon. Appl Environ Microbiol. 2001; 67: 561-568.

5. Garcia-Migura L, Hendriksen RS, Fraile L, Aarestrup FM. Antimicrobial resistance of zoonotic and commensal bacteria in europe: The missing link between consumption and resistance in veterinary medicine. Vet Microbiol. 2014; 170: 1-9.

6. Cabello FC, Godfrey HP, Tomova A, Ivanova L, Dölz H, Millanao A, Buschmann AH. Antimicrobial use in aquaculture re-examined: Its relevance to antimicrobial resistance and to animal and human health. Environ Microbiol. 2013; 15: 1917-1942.

7. Duffy B, Holliger E, Walsh F. Streptomycin use in apple orchards did not increase abundance of mobile resistance genes. FEMS Microbiol Lett. $2014 ; 350$ : 180-189.

8. Nguyen F, Starosta AL, Arenz S, Sohmen D, Donhofer A, Wilson DN. Tetracycline antibiotics and resistance mechanisms. Biological chemistry. 2014 ; 395: 559-575.

9. Roberts MC. Mechanism of resistance for characterized tet and otr genes. http://faculty.Washington.Edu/marilynr/tetweb1.Pdf (modified: July 2016; date accessed: December 2016)
10. Poulsen SM, Kofoed C, Vester B. Inhibition of the ribosomal peptidyl transferase reaction by the mycarose moiety of the antibiotics carbomycin, spiramycin and tylosin. J Mol Biol. 2000; 304: 471-481.

11. Cocito C, Di Giambattista M, Nyssen E, Vannuffel P. Inhibition of protein synthesis by streptogramins and related antibiotics. Antimicrob Agents Chemother. 1997; 39 Suppl A, 7-13.

12. Hraoui M, Boutiba-Ben Boubaker I, Rachdi M, Slim A, Ben Redjeb S. Macrolide and tetracycline resistance in clinical strains of Streptococcus agalactiae isolated in Tunisia. J Med Microbiol. 2012; 61: 1109-1113.

13. Marimon JM, Valiente A, Ercibengoa M, García-Arenzana JM, PerezTrallero E. Erythromycin resistance and genetic elements carrying macrolide efflux genes in Streptococcus agalactiae. Antimicrob Agents Chemother. 2005; 49: 5069-5074.

14. Roberts MC. Mechanisms of $m l s$ resistance (including nonpublished). http://faculty.Washington. Edu/marilynr/ermweba.Pdf (modified: July 2016; date accessed: December2016).

15. Aminov RI. Biotic acts of antibiotics. Frontiers in Microbiology. 2013; 4: 241.

16. European Centre for Disease Prevention and Control. Antimicrobial resistance surveillance in Europe 2014. 2015.

17. Rodriguez-Avial I, Rodriguez-Avial C, Culebras E, Picazo JJ. Distribution of tetracycline resistance genes tet $(m), \operatorname{tet}(o), \operatorname{tet}(l)$ and tet $(k)$ in blood isolates of viridans group streptococci harbouring erm(b) and mef(a) genes. Susceptibility to quinupristin/dalfopristin and linezolid. Int J Antimicrob Agents. 2003; 21: 536-541.

18. Seral C, Castillo FJ, Rubio-Calvo MC, Fenoll A, Garcia C, Gomez-Lus R. Distribution of resistance genes tet(m), aph3 '-iii, cat(pc194) and the integrase gene of Tn1545 in clinical Streptococcus pneumoniae harbouring erm (b) and mef(a) genes in Spain. J Antimicrob Chemother. 2001; 47: 863-866.

19. Roberts AP, Mullany P. Tn916-like genetic elements: A diverse group of modular mobile elements conferring antibiotic resistance. FEMS Microbiol Rev. 2011; 35: 856-871.

20. Del Grosso M, Scotto D’abusco A, Iannelli F, Pozzi G, Pantosti A. Tn2009, a Tn916-like element containing mef(e) in Streptococcus pneumoniae. Antimicrob Agents Chemother. 2004; 48: 2037-2042.

21. Li Y, Tomita H, Lv Y, Liu J, Xue F, Zheng B, Ike Y. Molecular characterization of erm(b)- and mef(e)-mediated erythromycinresistant Streptococcus pneumoniae in China and complete DNA sequence of Tn2010. J Appl Microbiol. 2011; 110: 254-265.

22. Roberts MC. Update on macrolide-lincosamide-streptogramin, ketolide, and oxazolidinone resistance genes. FEMS Microbiol Lett. 2008; 282: 147-159.

23. Franke AE, Clewell DB. Evidence for a chromosome-borne resistance transposon (Tn916) in Streptococcus faecalis that is capable of "conjugal" transfer in the absence of a conjugative plasmid. J Bacteriol. 1981; 145: 494-502.

24. Santoro F, Vianna ME, Roberts AP. Variation on a theme; an overview of the Tn916/Tn1545 family of mobile genetic elements in the oral and nasopharyngeal streptococci. Antimicrobials, Resistance and Chemotherapy. 2014; 5: 535.

25. Johnsen PJ, Townsend JP, Bohn T, Simonsen GS, Sundsfjord A, Nielsen KM. Factors affecting the reversal of antimicrobial-drug resistance. Lancet Infectious Diseases. 2009; 9: 357-364.

26. Shaw JH, Clewell DB. Complete nucleotide sequence of macrolidelincosamide-streptogramin b-resistance transposon Tn917 in Streptococcus faecalis. J Bacteriol. 1985; 164: 782-796.

27. Del Grosso M, Camilli R, Iannelli F, Pozzi G, Pantosti A. The mef(e)carrying genetic element (mega) of Streptococcus pneumoniae: Insertion sites and association with other genetic elements. Antimicrob Agents Chemother. 2006; 50: 3361-3366.

28. Poyartsalmeron C, Trieucuot P, Carlier C, Courvalin P. Nucleotidesequences specific for Tn1545-like conjugative transposons in pneumococci and staphylococci resistant to tetracycline. Antimicrob Agents Chemother. 1991; 35: 1657-1660.

29. Rice LB, Carias LL. Transfer of Tn 5385 , a composite, multiresistance chromosomal element from Enterococcus faecalis. J Bacteriol. 1998; 180: 714-721.

30. Cochetti I, Tili E, Mingoia M, Varaldo PE, Montanari MP.Erm(b)carrying elements in tetracycline-resistant pneumococci and correspondence between Tn1545 and Tn6003. Antimicrob Agents Chemother. 2008; 52: 1285-1290.

31. De Vries LE, Valles Y, Agerso Y, Vaishampayan PA, Garcia-Montaner A, Kuehl JV, Christensen H, Barlow M, Francino MP. The gut as reservoir of antibiotic resistance: Microbial diversity of tetracycline resistance in mother and infant. PLoS ONE. 2011; 6, e21644. 
32. Palmieri C, Mingoia M, Massidda O, Giovanetti E, Varaldoa PE. Streptococcus pneumoniae transposon Tn1545/Tn6003 changes to Tn6002 due to spontaneous excision in circular form of the erm(b)and apha3-containing macrolide-aminoglycoside-streptothricin (mas) element. Antimicrob Agents Chemother. 2012; 56: 5994-5997.

33. Warburton PJ, Palmer RM, Munson MA, Wade WG. Demonstration of in vivo transfer of doxycycline resistance mediated by a novel transposon. J Antimicrob Chemother. 2007; 60: 973-980.

34. Whittle G, Hund BD, Shoemaker NB, Salyers AA. Characterization of the 13-kilobase erm(f) region of the bacteroides conjugative transposon CTNDOT. Appl Environ Microbiol. 2001; 67: 3488-3495.

35. Gupta A, Vlamakis H, Shoemaker N, Salyers AA. A new bacteroides conjugative transposon that carries an erm(b) gene. Appl Environ Microbiol. 2003; 69: 6455-6463.

36. Moore IF, Hughes DW, Wright GD. Tigecycline is modified by the flavin-dependent monooxygenase tet(x). Biochemistry. 2005; 44: 11829-11835.

37. Aminov RI. Evolution in action: Dissemination of tet(x) into pathogenic microbiota. Frontiers in Microbiology. 2013; 4.

38. Leski TA, Bangura U, Jimmy DH, Ansumana R, Lizewski SE, Stenger $\mathrm{DA}$, Taitt CR, Vora GJ. Multidrug-resistant tet(x)-containing hospital isolates in Sierra Leone. Int J Antimicrob Agents. 2013; 42: 83-86.

39. Del Grosso M, Camilli R, Libisch B, Fuzi M, Pantosti A. New composite genetic element of the $\operatorname{tn} 916$ family with dual macrolide resistance genes in a streptococcus pneumoniae isolate belonging to clonal complex 271. Antimicrob Agents Chemother. 2009; 53: 1293-1294.

40. Brenciani A, Bacciaglia A, Vecchi M, Vitali LA, Varaldo PE, Giovanettil E. Genetic elements carrying erm(b) in Streptococcus pyogenes and association with tet $(\mathrm{m})$ tetracycline resistance gene. Antimicrob Agents Chemother. 2007; 51: 1209-1216.

41. Cochetti I, Tili E, Vecchi M, Manzin A, Mingoia M, Varaldo PE, Montanari MP. New Tn916-related elements causing erm (b)-mediated erythromycin resistance in tetracycline-susceptible pneumococci. J Antimicrob Chemother. 2007; 60: 127-131.

42. Santoro F, Oggioni MR, Pozzi G, Iannelli F. Nucleotide sequence and functional analysis of the tet (m)-carrying conjugative transposon Tn5251 of Streptococcus pneumoniae. FEMS Microbiol Lett. 2010; 308: $150-158$

43. Mingoia M, Tili E, Manso E, Varaldo PE, Montanari MP. Heterogeneity of Tn5253-like composite elements in clinical Streptococcus pneumoniae isolates. Antimicrob Agents Chemother. 2011; 55: 1453-1459.

44. Giovanetti E, Brenciani A, Tiberi E, Bacciaglia A, Varaldo PE. ICESP2905, the erm(tr)-tet(o) element of Streptococcus pyogenes, is formed by two independent integrative and conjugative elements. Antimicrob Agents Chemother. 2012; 56: 591-594.

45. Giovanetti E, Brenciani A, Lupidi R, Roberts MC, Varaldo PE. Presence of the tet(o) gene in erythromycin- and tetracycline-resistant strains of Streptococcus pyogenes and linkage with either the mef(a) or the erm (a) gene. Antimicrob Agents Chemother. 2003; 47: 2844-2849.

46. Brenciani A, Bacciaglia A, Vignaroli C, Pugnaloni A, Varaldo PE, Giovanetti E. Phi m46.1, the main Streptococcus pyogenes element carrying mef(a) and tet(o) genes. Antimicrob Agents Chemother. 2010; 54: 221-229.

47. Martel A, Decostere A, Leener ED, Marien M, Graef ED, Heyndrickx M, Goossens H, Lammens C, Devriese LA, Haesebrouck F. Comparison and transferability of the erm(b) genes between human and farm animal streptococci. Microbial Drug Resistance. 2005; 11: 295-302.

48. Vignaroli C, Zandri G, Aquilanti L, Pasquaroli S, Biavasco F. Multidrugresistant enterococci in animal meat and faeces and co-transfer of resistance from an Enterococcus durans to a human Enterococcus faecium. Curr Microbiol. 2011; 62: 1438-1447.

49. Jasni AS, Mullany P, Hussain H, Roberts AP. Demonstration of conjugative transposon (Tn5397)-mediated horizontal gene transfer between Clostridium difficile and Enterococcus faecalis. Antimicrob Agents Chemother. 2010; 54: 4924-4926.
50. Wasels F, Monot M, Spigaglia P, Barbanti F, Ma L, Bouchier C, Dupuy B, Mastrantonio P. Inter- and intraspecies transfer of a Clostridium difficile conjugative transposon conferring resistance to $\mathrm{MLS}_{\mathrm{B}}$. Microbial Drug Resistance. 2014; 20: 555-560.

51. Florez AB, Ammor MS, Mayo B. Identification of tet $(\mathrm{m})$ in two Lactococcus lactis strains isolated from a spanish traditional starterfree cheese made of raw milk and conjugative transfer of tetracycline resistance to lactococci and enterococci. Int J Food Microbiol. 2008; 121: 189-194.

52. Rizzotti L, La Gioia F, Dellaglio F, Torriani S. Molecular diversity and transferability of the tetracycline resistance gene tet $(\mathrm{m})$, carried on Tn916-1545 family transposons, in enterococci from a total food chain. Antonie Van Leeuwenhoek International Journal of General and Molecular Microbiology. 2009; 96: 43-52.

53. Gazzola S, Fontana C, Bassi D, Cocconcelli PS. Assessment of tetracycline and erythromycin resistance transfer during sausage fermentation by culture-dependent and -independent methods. Food Microbiol. 2012; 30: 348-354.

54. Cocconcelli PS, Cattivelli D, Gazzola S. Gene transfer of vancomycin and tetracycline resistances among Enterococcus faecalis during cheese and sausage fermentations. Int J Food Microbiol. 2003; 88: 315-323.

55. Gevers D, Huys G, Swings J. In vitro conjugal transfer of tetracycline resistance from Lactobacillus isolates to other gram-positive bacteria. FEMS Microbiol Lett. 2003; 225: 125-130.

56. Ojo KK, Ruehlen NL, Close NS, Luis H, Bernardo M, Leitao J, Roberts MC. The presence of a conjugative gram-positive Tn2009 in gramnegative commensal bacteria. J Antimicrob Chemother. 2006; 57: 1065-1069.

57. Iannelli F, Santoro F, Oggioni MR, Pozzi G. Nucleotide sequence analysis of integrative conjugative element Tn5253 of Streptococcus pneumoniae. Antimicrob Agents Chemother. 2014; 58: 1235-1239.

58. Boguslawska J, Zycka-Krzesinska J, Wilcks A, Bardowski J. Intra- and interspecies conjugal transfer of Tn916-like elements from Lactococcus lactis in vitro and in vivo. Appl Environ Microbiol. 2009; 75: 6352-6360.

59. McCarthy AJ, Loeffler A, Witney AA, Gould KA, Lloyd DH, Lindsay JA. Extensive horizontal gene transfer during Staphylococcus aureus co-colonization in vivo. Genome Biology and Evolution. 2014; 6: 2697-2708.

60. Moubareck C, Bourgeois N, Courvalin P, Doucet-Populaire F. Multiple antibiotic resistance gene transfer from animal to human enterococci in the digestive tract of gnotobiotic mice. Antimicrob Agents Chemother. 2003; 47: 2993-2996.

61. Doucet-Populaire F, Trieu-Cuot P, Dosbaa I, Andremont A, Courvalin P. Inducible transfer of conjugative transposon Tn 1545 from Enterococcus faecalis to Listeria monocytogenes in the digestive tracts of gnotobiotic mice. Antimicrob Agents Chemother. 1991; 35: 185-187.

62. Jacobsen L, Wilcks A, Hammer K, Huys G, Gevers D, Andersen SR. Horizontal transfer of tet $(\mathrm{m})$ and $\operatorname{erm}(\mathrm{b})$ resistance plasmids from food strains of Lactobacillus plantarum to Enterococcus faecalis jh2-2 in the gastrointestinal tract of gnotobiotic rats. FEMS Microbiol Ecol. 2007; 59: 158-166.

63. Marosevic D, Cervinkova D, Vlkova H, Videnska P, Babak V, Jaglic Z. In vivo spread of macrolide-lincosamide-streptogramin B $\left(\mathrm{MLS}_{\mathrm{B}}\right)$ resistance-a model study in chickens. Vet Microbiol. 2014; 171: 388-396.

64. De Leener E, Martel A, Decostere A, Haesebrouck F. Distribution of the erm (b) gene, tetracycline resistance genes, and Tn1545-like transposons in macrolide- and lincosamide-resistant enterococci from pigs and humans. Microbial Drug Resistance-Mechanisms Epidemiology and Disease. 2004; 10: 341-345.

65. Sorensen TL, Blom M, Monnet DL, Frimodt-Moller N, Poulsen RL, Espersen F. Transient intestinal carriage after ingestion of antibioticresistant Enterococcus faecium from chicken and pork. New England Journal of Medicine. 2001; 345: 1161-1166. 